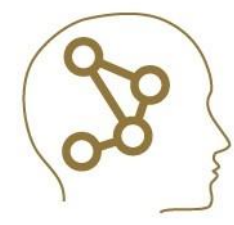

\title{
Deep Learning-Based Prediction of Obesity Levels According to Eating Habits and Physical Condition
}

\author{
Mehmet Kivrak (D) \\ Inonu University, Faculty of Medicine Dept. of Biostatistics and Medical Informatics,Malatya, Turkey. (e-mail: mehmetkivrak83@gmail.com).
}

\section{ARTICLE INFO}

Received: March.,08.202

Revised: April.,05.2021

Accepted: May.,21.2021

Keywords:

Obesity

Obesity Levels

Eating Habits

Deep Learning

Corresponding author: Mehmet

Kivrak

$\triangle$ mehmetkivrak83@gmail.com

湎 +905335113432

ISSN: 2548-0650

DOI: https://doi.org/10.52876/jcs.939875

\begin{abstract}
Obesity occurs as a result of excessive fat storage in the body and brings along physical and mental problems [1]. The physical function has been associated with impaired quality of life in various areas such as distress in society, sexual function, self-esteem, and work-related quality of life [2]. The prevalence of obesity has been steadily increasing over the past few decades and is now unprecedented. This increase has occurred in almost all ages, genders, and races. These data show that the segments of individuals in the highest weight categories i.e. (BMI $>40 \mathrm{~kg} / \mathrm{m} 2$ ) increased proportionally more than those in the lower BMI categories (BMI $<35 \mathrm{~kg} / \mathrm{m} 2$ ) [3]. Given the numerous and important health consequences associated with obesity, there is an urgent need to develop highly effective interventions aimed at reversing these "obesogenic" drivers, including both government policies and health education and development programs. It is important to implement measures to be taken, including both government policies and health education and development programs, especially during the COVID-19 pandemic process we are in. In this study, the data set on the open-source access website was used for the prediction of obesity levels and consists of patient records of 17 variables created by the deep learning repository. In addition, the performance of deep learning methods in the prediction of obesity levels was examined and determined. Performance evaluation of models is compared in terms of accuracy, Fleiss's kappa, classification error, and absolute error.
\end{abstract}

\section{INTRODUCTION}

$\mathrm{T}$ HE international incidence of obesity and weight problems has doubled because 1980 to an extent that virtually a third of the arena populace is now categorized as obese or chubby [4]. Weight problems adversely impact nearly all physiological functions of the physique and include a huge public health threat [5]. The World Health Organization (WHO) defines obese and obesity as irregular or immoderate fat accumulation that offers a hazard to wellness. Obesity occurs as a result of excessive fat storage in the body and brings along physical and mental problems [1]. The physical function has been associated with impaired quality of life in various areas such as distress in society, sexual function, self-esteem, and work-related quality of life [2]. The prevalence of obesity has been steadily increasing over the past few decades and is now unprecedented. This increase has occurred in almost all ages, genders, and races. These data show that the segments of individuals in the highest weight categories i.e. (BMI $>40 \mathrm{~kg} / \mathrm{m} 2$ ) increased proportionally more than those in the lower BMI categories (BMI $<35 \mathrm{~kg} /$ $\mathrm{m} 2$ ) [3]. Given the numerous and important health consequences associated with obesity, there is an urgent need to develop highly effective interventions aimed at reversing these "obesogenic" drivers, including both government policies and health education and development programs. It is important to implement measures to be taken, including both government policies and health education and development programs, especially during the COVID-19 pandemic process we are in.

In this study, the data set on the open-source access website was used for the prediction of obesity levels and consists of patient records of 17 variables created by the deep learning repository. In addition, the performance of deep learning methods in the prediction of obesity levels was examined and determined. Performance evaluation of models is compared in terms of accuracy, Fleiss's kappa, classification error, and absolute error.

\section{MATERIAL AND METHOD \\ 1.1.2.1. Data Set}

The dataset used for the analysis was obtained from https://archive.ics.uci.edu/ml/datasets[6]. The dataset includes data for estimating obesity levels in people between the ages of 14 and 61 years with various eating habits and physical conditions in Mexico, Peru, and Colombia countries 
and consists of patient records of 17 variables. After all, the calculation was made to obtain the mass body index (BMI) for each individual, the results were compared with the data provided by WHO and the Mexican Normativity [6]. A detailed explanation of the variables is given in Table I.

TABLE 1

THE DETAIL EXPLANATION OF THE VARIABLES

\begin{tabular}{|c|c|}
\hline Variables & Explanation \\
\hline Obesity & Target (1:Insufficient Weight (BMI<18.5), 2:Normal \\
\hline Level & $\begin{array}{l}\text { Weight ( } 18.5 \text { to } 24.9), 3: \text { Overweight ( } 25 \text { to } 29.9 \text { ), } \\
\text { 4:Obesity Type I ( } 30 \text { to } 34.9), 5: \text { Obesity Type II ( } 35 \text { to } \\
\text { 39.9), 6: Obesity Type III (BMI>40) }\end{array}$ \\
\hline Age & Age \\
\hline Gender & Gender (1:male, $0:$ female) \\
\hline Height & Height \\
\hline Weight & Weight \\
\hline History & Family History have overweight (1:Yes, $0:$ No) \\
\hline FAVC & Eat High Caloric Food Frequently (1:Yes, 0: No) \\
\hline FCVC & $\begin{array}{l}\text { Frequency Eating Vegetables (1:Never, 2:Sometimes, } \\
\text { 3:Always) }\end{array}$ \\
\hline $\mathrm{NCP}$ & $\begin{array}{l}\text { Number of main meals (Between } 1 \text { y } 2 \text {, Three, More than } \\
\text { three }\end{array}$ \\
\hline CAEC & $\begin{array}{l}\text { Consumption of food between meals ( } 0: \text { No, } 1 \text { :Sometimes, } \\
\text { 2:Frequently, 3:Always) }\end{array}$ \\
\hline Smoke & Smoking (1:Yes, 0: No) \\
\hline $\mathrm{CH} 2 \mathrm{O}$ & $\begin{array}{l}\text { Consumption of water daily (Less than a liter, between } \\
\text { land } 2 \mathrm{Lt} \text {, More than } 2 \mathrm{Lt}\end{array}$ \\
\hline $\mathrm{SCC}$ & $\begin{array}{l}\text { The attributes related to the physical condition are: } \\
\text { Calories consumption monitoring ( } 1 \text { :Yes, } 0: \text { No) }\end{array}$ \\
\hline FAF & $\begin{array}{l}\text { Physical activity frequency (Not have, } 1 \text { or } 2 \text { days, } 2 \text { or } 4 \\
\text { days, } 4 \text { or } 5 \text { days) }\end{array}$ \\
\hline TUE & $\begin{array}{l}\text { Time using technology devices ( } 0-2 \text { hours, } 3-5 \text { hours, } \\
\text { More than } 5 \text { hours) }\end{array}$ \\
\hline CALC & $\begin{array}{l}\text { Consumption of alcohol (0:No, 1:Sometimes, } \\
\text { 2:Frequently, 3:Always) }\end{array}$ \\
\hline MTRANS & $\begin{array}{l}\text { Transportation used (1:Automobile, 2:Motorbike, 3:Bike, } \\
\text { 4: Public Transportation, 5:Walking) }\end{array}$ \\
\hline
\end{tabular}

\subsection{Knowledge Discovery in Databases (KDD)}

In the process of KDD; data selection (obesity dataset), data preprocessing (extreme and missing value analyses), data transformation (normalization, etc.), data mining and evaluation, and interpretation of the results were performed.

\subsection{Deep Learning}

Deep Learning can mechanically extract function representation from raw data, which is a new method of desktop finding out derived from artificial neural networks [7]. DL learns characteristic hierarchies with better hierarchy elements with a blend of low-degree aspects. Therefore, DL effectually solves problematic and extreme dimensional problems It's used. Convolutional Neural network (CNN) is one of the most positive deep studying units [8].

$$
Z_{i, j, k}^{l}=w_{k}^{l^{T}} x_{i, j}^{l}+b_{k}^{l}
$$

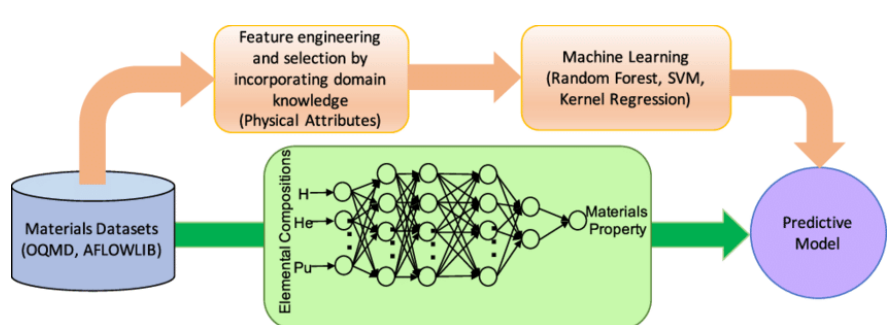

Fig.1. Comparison of Deep Learning Approach With Conventional NN.
The worth of the region of the layer 1 and its place within the $k$ characteristic map (i, j), $Z_{i, j, k}^{l}$ can be estimated as shown in equation 1 .

The place $\mathrm{w}_{\mathrm{k}}^{\mathrm{l}}$ and $\mathrm{b}_{\mathrm{k}}^{\mathrm{l}}$ are $l^{\text {th }}$, lth layers within the $\mathrm{k}$ property map are the weight vector and the bias. The activation value $\mathrm{a}_{\mathrm{i}, \mathrm{j}, \mathrm{k}}^{\mathrm{l}}$ for the convolution feature $\mathrm{Z}_{\mathrm{i}, \mathrm{j}, \mathrm{k}}^{\mathrm{l}}$ can be expressed, as shown in equation 2 [8].

$$
a_{i, j, k}^{l}=\mathrm{a}\left(Z_{i, j, k}^{l}\right)
$$

Hyperparameters of the deep learning model are epsilon, rho, L1, L2, max w2, and dropout, which are tuned by using a grid search optimization algorithm.

\subsection{Performance Metrics}

Accuracy (AC) is outlined because the division of values incompatible eyes via the whole number of observations and is indicated via equation 3 .

$$
A C=\frac{T P+T N}{T P+T N+F N+F P}
$$

Fleiss's kappa coefficient is a generalization of Scott's pi coefficient, which examines the problem of matching two valuers [9]. Similarly, it is related to Cohen's kappa coefficient [10]. However, while Scott's pi coefficient and Cohen's kappa coefficient require two valuers, Fleiss's kappa coefficient can be applied to any number of values greater than two. Just like them, it is expressed numerically between the values of 0 and 1 how much the match between a fixed number of values is not a matter of randomness and therefore how reliable it is [11].

Absolute Error is the amount of error in your measurements. It is the difference between the measured value and the "true" value [12].

\section{RESULTS}

\subsection{Statistical Analysis}

Quantitative data were summarized as the arithmetic means with standard deviation, median with min and max values, and qualitative data as numbers by percentage. After the suitability of the data to multiple normal distributions, the difference between the groups in normally distributed groups was examined by t-test in independent samples and the Kruskal Wallis H-test for variables that did not show normal distribution. When significant differences in categorical data were determined among the groups $(p<0.05)$, pairwise comparisons were performed by the Bonferroni-adjusted Pearson chi-square test. Upon seeing significant differences $(\mathrm{p}<0.001)$ in the Kruskal Wallis H test, pairwise comparisons of the groups with significant differences were identified using the post-hoc Conover multiple comparison test. For statistical analysis, IBM SPSS version 22 [13], RStudio version 1.1.463 [14], and Rapid Miner Studio version 8.1.001 [15] were used.

\subsection{2. Data Mining}

In this study, the performance of deep learning methods in the prediction of obesity levels was examined and determined. Performance evaluation of models is compared in 
terms of accuracy, Fleiss's kappa, classification error, and absolute error.

\subsection{3. Model Development}

The 10-fold cross-validation method was used in the performance evaluation of all classifier methods to verify the quality of the models. Cross-validation is the re-sampling procedure used to evaluate machine learning models in a data sample. The procedure has a single parameter named $\mathrm{k}$ that expresses the number of groups to split a given data sample. In 10-fold cross-validation, the models are trained and tested ten different times, and then, mean performance metrics (i.e., accuracy, precision, and so on) are estimated at the end of the process [16].

\subsubsection{Evaluation of the Models}

Hyperparameters of the deep learning model were 1.0E8 for epsilon, 0.99 for rho, 1.0E-5 for L1, 0.0 for L2, 10.0 for max w2, and 0.15 for dropout, respectively. Figure 2 depicts the pseudo-codes of $\mathrm{CNN}$ in the deep learning algorithm.

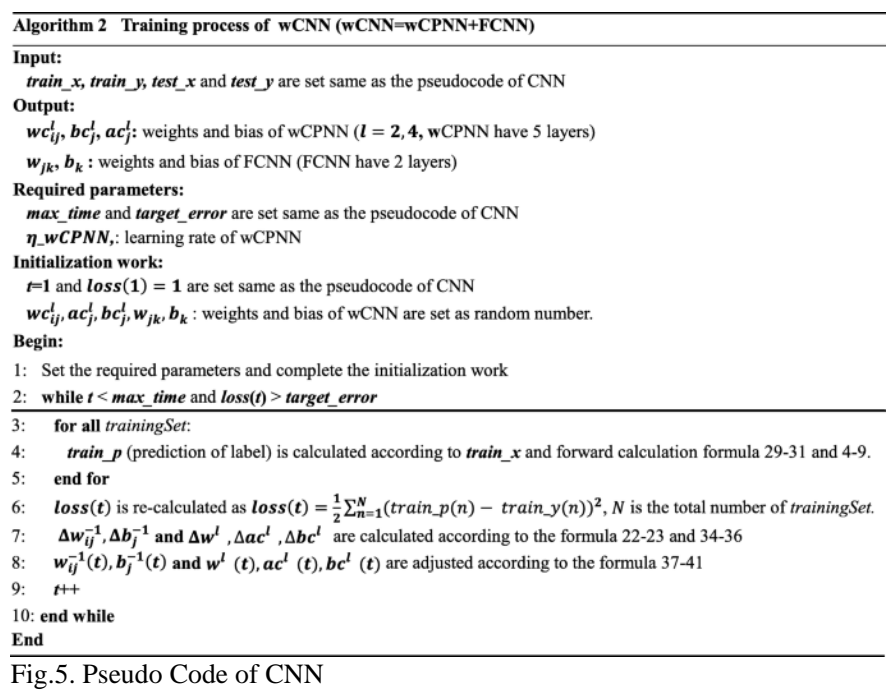

Which variable is more important in the deep learning algorithm is calculated and presented in table II.

TABLE II:

VARIABLE IMPORTANCE OF DEEP LEARNING

\begin{tabular}{ll} 
Variable & Relative İmportance \\
\hline Weight & 0.75 \\
FCVC & 0.36 \\
Gender & 0.29 \\
Family His. & 0.21 \\
Age & 0.21 \\
CAEC & 0.18 \\
NCP & 0.14 \\
FAF & 0.11 \\
CALC & 0.10 \\
Height & 0.10 \\
TUE & 0.10 \\
FAVC & 0.08 \\
CH2O & 0.07 \\
MTRANS & 0.07 \\
SCC & 0.04 \\
SMOKE & 0.01 \\
\hline
\end{tabular}

Table II and figure 2. tabulates the importance levels of variables in obesity levels in the deep learning modeling. Weight (0.75), FCVC (0.36), Gender (0.29), Family His. (0.21), Age (0.21), and CAEC (0.18) were calculated from deep learning. In comparison, the lowest relative significance was estimated for Smoke (0.01) from deep learning.

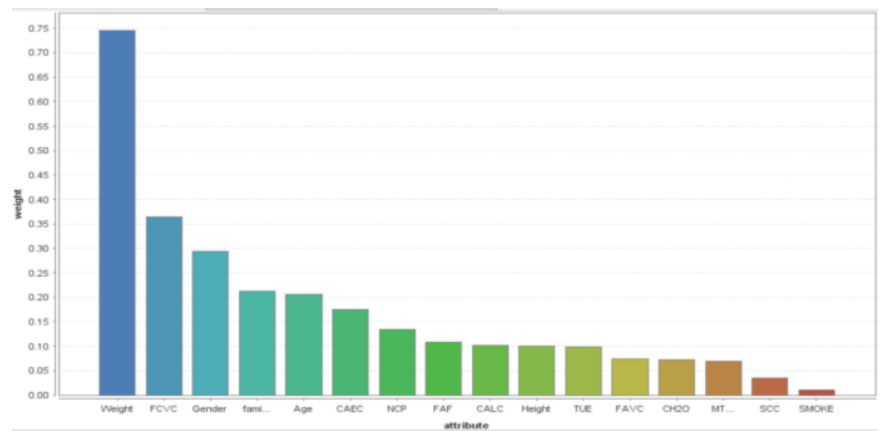

Fig.2. Variable Importance of Deep Learning

\subsection{5. General Assessment}

According to the general assessment, the deep learning method provided the 0.82 accuracy value, 0.78 Kappa value, 0.18 classification error value, and 0.28 absolute error value. The performance metrics of the deep learning method presented in Table 3.

TABLE 3

MODEL PERFORMANCE METRICS

\begin{tabular}{lllll}
\hline & $\begin{array}{l}\text { Accuracy } \\
(\%)\end{array}$ & $\begin{array}{l}\text { F.Kappa } \\
(\%)\end{array}$ & $\begin{array}{l}\text { Clas.Error } \\
(\%)\end{array}$ & $\begin{array}{l}\text { A. Error } \\
(\%)\end{array}$ \\
\hline Deep Learning & $\mathbf{8 2 . 0}$ & $\mathbf{0 . 7 8}$ & $\mathbf{1 8 . 0}$ & $\mathbf{2 8 . 1}$ \\
\hline
\end{tabular}

Figure 3. shows that in the classification process performed with deep learning approaches the correct positive, and negative rates in the deep learning algorithm, according to the confusion matrix.

\begin{tabular}{|c|c|c|c|c|c|c|c|}
\hline & tue 2 & tue 3 & true 4 & true 1 & tue 5 & tue 6 & dass pred \\
\hline pred. 2 & 116 & 39 & 0 & 5 & 0 & 0 & $72.50 \%$ \\
\hline pred 3 & 30 & 466 & 40 & 0 & 3 & 0 & $86.46 \%$ \\
\hline pred. 4 & 0 & 67 & 270 & 0 & 9 & 2 & $77.59 \%$ \\
\hline pred. 1 & 141 & 7 & 0 & 267 & 0 & 0 & $64.34 \%$ \\
\hline pred. 5 & 0 & 1 & 40 & 0 & 285 & 1 & $87.16 \%$ \\
\hline pred 6 & 0 & 0 & 1 & 0 & 0 & 321 & $99.69 \%$ \\
\hline dass recall & $40.42 \%$ & $80.34 \%$ & $76.92 \%$ & $98.16 \%$ & $95.96 \%$ & $99.07 \%$ & \\
\hline
\end{tabular}

Fig.3. Confusion Matrix for the Model

\section{CONCLUSION}

Obesity is increasing all over the world due to urbanization, economic development, and lifestyle changes and is considered an epidemic health problem. In addition to the life-threatening diseases it has caused, it is understood how serious a public health problem it is when the negative effects of obesity on COVID 19 are seen in these extraordinary days that our world is going through. Individuals with asthma, chronic lung disease, diabetes, heart, and chronic kidney disease are at higher risk for COVID 19. Obesity plays a key role in the development of these chronic diseases (diabetes, heart diseases, asthma, etc.). These features of obesity suggest that it is one of the important factors for the increased risk of death in COVID-19 patients. In this study, using methods based on deep learning, eating habits and physical condition values and obesity levels were tried to be accurately predicted and the most important variables affecting the obesity risk level were determined. In the next period, studies on the 
relationship between obesity and COVID 19 in terms of risk factors are recommended.

\section{ACKNOWLEDGMENT}

I would like to thank to my supervisor Prof. Cemil Çolak.

\section{REFERENCES}

[1] Deniz, S., Şirin, H., Kıvrak, M., Kaplan, Z., Ketrez, G., \& Üner, S. (2020). Factors associated with overweight and obesity in students of 5-14 age group in Mersin. Gülhane Tip Dergisi, 62(4), 245.

[2] Fontaine, K. R., Bartlett, S. J., \& Barofsky, I. (2000). Health-related quality of life among obese persons seeking and not currently seeking treatment. International Journal of Eating Disorders, 27(1), 101-105.

[3] Wright, S. M., \& Aronne, L. J. (2012). Causes of obesity. Abdominal Radiology, 37(5), 730-732.

[4] Global Burden of Disease Collaborative Network. (2017). Global Burden of Disease Study 2015 (GBD 2015) Obesity and Overweight Prevalence 1980-2015.

[5] Singh, G. M., Danaei, G., Farzadfar, F., Stevens, G. A., Woodward, M., Wormser, D., ... \& Prospective Studies Collaboration (PSC). (2013). The age-specific quantitative effects of metabolic risk factors on cardiovascular diseases and diabetes: a pooled analysis. PloS one, 8(7), e65174.

[6] Palechor, F. M., \& de la Hoz Manotas, A. (2019). Dataset for estimation of obesity levels based on eating habits and physical condition in individuals from Colombia, Peru and Mexico. Data in brief, $25,104344$.

[7] Li, Y., Nie, X., \& Huang, R. (2018). Web spam classification method based on deep belief networks. Expert Systems with Applications, 96, 261-270.

[8] Gu, J., Wang, Z., Kuen, J., Ma, L., Shahroudy, A., Shuai, B., ... \& Chen, T. (2018). Recent advances in convolutional neural networks. Pattern Recognition, 77, 354-377.

[9] Scott, W. A. (1955). Reliability of content analysis: The case of nominal scale coding. Public opinion quarterly, 321-325.

[10] Cohen, J. (1960). A coefficient of agreement for nominal scales. Educational and psychological measurement, 20(1), 37-46.

[11] Fleiss, J. L. (1971). Measuring nominal scale agreement among many raters. Psychological bulletin, 76(5), 378.

[12] Findley, D. F., Kotz, S., Read, C. B., Balakrishnan, N., Vidakovic, B., \& Johnson, N. L. (2006). Encyclopedia of Statistical Sciences.

[13] Yaşar, Ş., Arslan, A., Colak, C., \& Yoloğlu, S. (2020). A Developed Interactive Web Application for Statistical Analysis: Statistical Analysis Software. Middle Black Sea Journal of Health Science, 6(2), 227-239.

[14] Campbell, M. (2019). RStudio Projects. In Learn RStudio IDE (pp. 3948). Apress, Berkeley, CA

[15] Hofmann, M., \& Klinkenberg, R. (Eds.). (2016). RapidMiner: Data mining use cases and business analytics applications. CRC Press.

[16] Yadav, S., \& Shukla, S. (2016, February). Analysis of k-fold crossvalidation over hold-out validation on colossal datasets for quality classification. In 2016 IEEE 6th International conference on advanced computing (IACC) (pp. 78-83). IEEE.

\section{BIOGRAPHIES}

Mehmet Kivrak obtained his BSc degree in statistics from Dokuz Eylul University (DEU) in 2001. He received the BSc. and MSc. diploma in Statistics from Dokuz Eylul University in 2001 and 2006 respectively, and $\mathrm{Ph} . \mathrm{D}$. degrees in the Graduate Department of Biostatistics and Medical Informatics of Inonu University in 2017. He was accepted as an expert statisticianTurkish Statistical Institute in 2009. His research interests are data mining, cognitive systems, reliability and genetics and bioengineering, and signal processing. His current research interests are genetics and bioengineering and data mining. 